\title{
Range of Critical Temperatures in Sick and Premature Newborn Babies
}

\author{
J. W. SCOPES and IQBAL AHMED \\ From the Nuffield Neonatal Research Unit, Institute of Child Health, Hammersmith Hospital, London W.12
}

The human baby, even if premature, shows evidence of homeothermy (Brück, 1961; Day, Curtis, and Kelly, 1943). When subjected to a cool environment, his metabolic rate increases in an attempt to keep pace with increased heat loss. When subjected to an excessively warm environment, he becomes restless and active with hurried panting respiration so that again metabolic rate is increased. Between these two extremes is a small range of thermal environment known as the neutral range where metabolic rate is minimal. Since the thermal environment depends on ambient air temperature, air flow rate, relative humidity, and radiant heat exchange, it is inadequate to express such an environment in terms of a single temperature-the 'environmental temperature', unless other factors are controlled or eliminated. In this study, conductive heat loss was limited by lying the baby on a napkin, air flow rate was constant at about $1 \mathrm{~m}$./ min., ambient vapour pressure (not relative humidity) was constant, and the walls of the baby chamber were opaque to radiant heat (for further details, see Scopes and Ahmed, 1966a).

Under these conditions and provided, (1) the baby is capable of a metabolic response to cold, and (2) the baby's colonic temperature remains essentially unchanged, one can define the neutral temperature in terms of environmental temperature by measuring $\mathrm{O}_{2}$ consumption rates at various environmental temperatures. The upper end of the range is inconstant because some infants in a very warm environment $\left(36^{\circ}-37^{\circ} \mathrm{C}\right.$.) remain sleeping with no immediate rise in rate of $\mathrm{O}_{2}$ consumption, despite a rapidly rising colonic temperature. The lower end of the range is known as the critical temperature. It varies with size, age, and clinical condition.

In the course of a study of rates of $\mathrm{O}_{2}$ consumption in babies (Scopes, 1965), critical temperatures were frequently assessed. Since a knowledge of the critical temperature of an individual baby is useful

Received January 31, 1966. (see discussion below), the range of critical temperatures found is reported here.

\section{Methods}

$\mathrm{O}_{2}$ consumption was measured in the closed circuit apparatus described previously (Scopes and Ahmed, 1966a). The babies were patients in the Nuffield Neonatal Research Unit or in the lying-in wards at Hammersmith Hospital, and were grouped as before (Scopes and Ahmed, 1966a).

Group I: Babies of more than 36 weeks' gestation, but excluding babies of Group II. Most of these babies were in the Neonatal Unit because of illness.

Group II: Babies of more than 36 weeks' gestation, but of a birthweight at least $750 \mathrm{~g}$. below the weight expected for gestation ('small for dates').

Group III: Babies of less than 36 weeks' gestation, but of birthweight more than $1,500 \mathrm{~g}$. ('larger prematures').

Group IV: Babies of birthweight less than 1,500 $\mathrm{g}$. ('smaller prematures').

Temperatures were measured as in the previous report (Scopes and Ahmed, 1966a). The 'environmental' temperature reported is that of the dry bulb air thermometer within the baby chamber. Critical temperature was assessed on over 100 occasions as follows. $\mathrm{O}_{2}$ consumption rates were measured at various environmental temperatures and plotted against those temperatures (Fig. 1). A horizontal line was drawn through the points of minimal consumption, and a second line taking in the points of metabolic response was drawn to intersect the first at the critical temperature. There are good theoretical reasons for accepting these arbitrary lines (Hill, 1961). The lines were drawn by eye, and usually it was easy to fit straight lines to the points. On other occasions as in Fig. 2, the points did not fit a straight line. None the less, drawing the possible lines was helpful, because even with the widest scatter of possible lines, the position of the critical temperature was usually fixed to $\pm 0 \cdot 5^{\circ} \mathrm{C}$. (see Fig. 2).

\section{Results}

The range of critical temperatures in three groups 


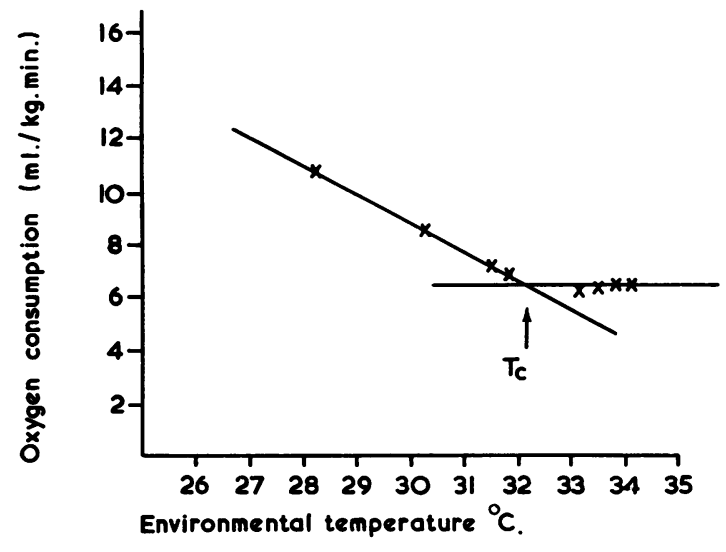

FIG. 1.-Assessment of critical temperature when metabolic rate at several different ambient temperatures has been measured. The two lines (see text) are drawn by eye to intersect at $T_{c}$-critical temperature.

of babies is shown in Fig. 3. In the first minutes after birth the baby, still wet from delivery, was found to have a rapid fall in body temperature, even in environmental temperatures of $35-36^{\circ} \mathrm{C}$. No systematic assessment of critical temperature was therefore made at this age. The small premature baby (Group IV) had a high critical temperature

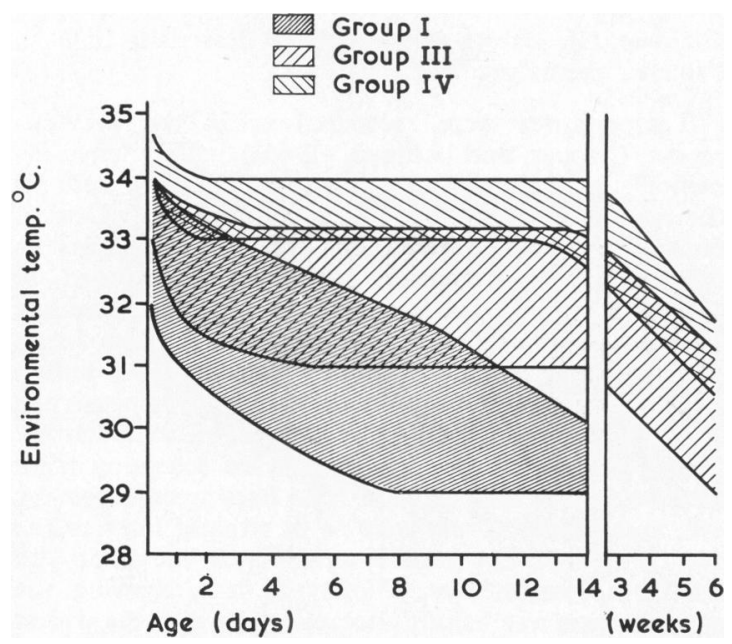

Fig. 3.-The range of critical temperatures found in three groups of babies (Group I of $>36$ weeks' gestation; Group III, the larger prematures; and Group IV, the smaller prematures), and the variation with age. Thermal conditions applying are described in text.

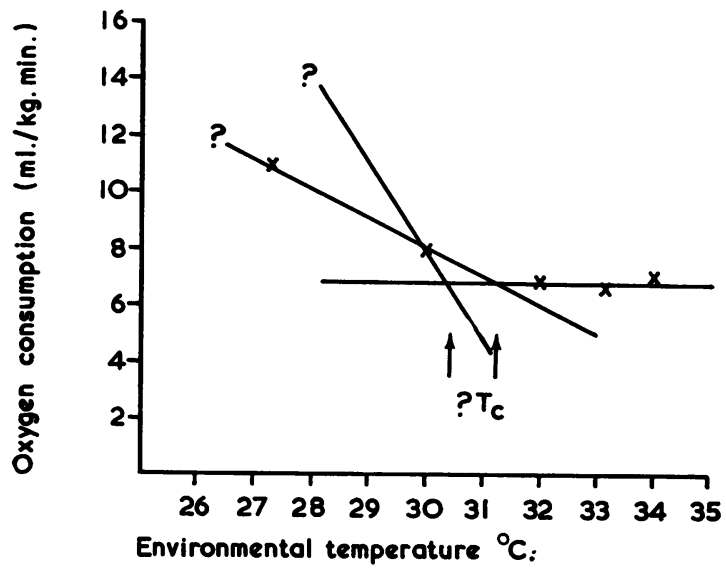

FIG. 2.-Estimation of critical temperature in a case where points do not conform to a straight line. Critical temperature can only be estimated approximately.

(34-34 $\cdot 7^{\circ} \mathrm{C}$.) between 12 and 24 hours of age. The range dropped to between $33-34^{\circ} \mathrm{C}$. in the next 24 hours, but unlike bigger babies it remained high for the next two weeks. The larger premature babies (Group III) showed a similar pattern with a slightly lower range. The Group I babies showed a more distinct tendency for the critical temperature to fall in the first days of life, and in general had a lower range than either previous group. The 'small for dates' babies (Group II) showed critical temperatures appropriate to their size rather than to their gestation.

\section{Discussion}

Inspection of Fig. 1 makes it clear that a rise in minimal rate of $\mathrm{O}_{2}$ consumption would be expected to be associated with a fall in critical temperature. Failure to conserve heat would be expected to cause a high critical temperature, and small babies have a relatively large surface area from which heat can be lost. They would, therefore, be expected to have a high critical temperature. These theoretical considerations are born out by the findings shown in Fig. 3.

Brück (1961) and Brück, Parmalee, and Brück (1962) found the neutral range for premature babies to be $32-34^{\circ} \mathrm{C}$. They did not report changes with age, nor did they attempt to distinguish between large and small premature babies. From Fig. 5 of the paper of Adamsons, Gandy, and James (1965) it appears that the critical temperature of term babies less than 4 hours old is $34-36^{\circ} \mathrm{C}$. Mestyán, Fekete, 
Bata, and Járai (1964) found the critical temperature of small premature babies $(1,000-2,000 \mathrm{~g}$.) to be at least $34 \cdot 5^{\circ} \mathrm{C}$. and those less than $1,500 \mathrm{~g}$. to be about $36^{\circ}$ C. Silverman and Agate (1964), using singlewalled incubators, found that ambient temperatures of $34^{\circ} \mathrm{C}$. were frequently heat-losing environments. However, direct comparisons between the work of these authors and the present study are suspect because other conditions (air flow rate, relative humidity, and radiant heat loss) vary from one worker to another.

Many of the earlier (and some recent, e.g. Přibylová and Znamenáček, 1964) measurements of $\mathrm{O}_{2}$ consumption were made with the baby clothed. All the processes of heat exchange are reduced by clothing the baby. We have found, for instance, that the temperature of ambient air inside clothing is frequently as high as $35^{\circ} \mathrm{C}$., even when the 'ambient' room temperature is only $26^{\circ} \mathrm{C}$. Presumably also relative humidity is comparatively high inside clothing, so work with clothed babies cannot be compared with these findings.

A knowledge of the critical temperature for an individual baby has a number of important consequences. (1) A baby who is in respiratory difficulties may be at the limit of his capacity to obtain oxygen from his atmosphere. Clearly arranging the thermal environment so that his needs are minimal is an advantage to such a baby. (2) Even a 'normal' premature baby loses heat in sub-neutral temperatures, so that over a period of hours his body temperature will fall. Numerous authors have shown that low body temperatures in babies are associated with high morbidity and mortality (e.g. Mann and Elliott, 1957; Silverman, Fertig, and Berger, 1958; Buetow and Klein, 1964; Day, Caliguiri, Kamenski, and Ehrlich, 1964). (3) Even if a baby can maintain a metabolic response to subneutral temperatures, he inevitably uses up reserves of substrate (fat, carbohydrate, etc.) at a time when he can ill afford it, so that reserves are depleted if a subsequent cold stress occurs. (4) For comparisons with work of other authors it is important that 'minimal' metabolic rates are measured in a neutral thermal environment. In some cases it is not possible, because of the child's condition, to spend time discovering the critical temperature for that individual baby. In that case metabolic rate must be measured in the neutral zone for babies of that size and gestation. (5) Occasionally, in tests of clinical usefulness, it is desirable to keep the baby at sub-neutral environmental temperatures for test periods (e.g. Scopes and Ahmed, 1966b). A knowledge of the critical temperature range enables one to arrange a sub-neutral environment without subjecting the baby to unnecessarily severe cold stress. Caution is necessary, however, in applying results, obtained in the standard conditions of a test chamber, to the baby under different thermal conditions in a commercial incubator.

\section{Summary}

The critical temperatures of sick and premature newborn babies found in the course of a wider study are reported.

We are grateful to Professor J. P. M. Tizard, Dr. J. A. Davis, and the resident medical and nursing staff for help, advice, and encouragement. We are also grateful to the Nuffield Foundation, and Heinz Ltd. for fellowships, and to the trustees of the Sir William Coxen Trust Fund for provisions of equipment.

\section{REFERENCES}

Adamsons, K., Jr., Gandy, G. M., and James, L. S. (1965). The influence of thermal factors upon oxygen consumption of the newborn human infant. F. Pediat., 66, 495.

Brück, K. (1961). Temperature regulation in the newborn baby. Biol. Neonat. (Basel), 3, 65.

_ , Parmalee, A. H., Jr., and Brück, M. (1962). Neutral temperature range and range of 'thermal comfort' in premature infants. ibid., 4, 32.

Buetow, K. C., and Klein, S. W. (1964). Effect of maintenance of 'normal' skin temperature on survival of infants of low birth weight. Pediatrics, 34, 163.

Day, R. L., Caliguiri, L., Kamenski, C., and Ehrlich, F. (1964). Body temperature and survival of premature infants. ibid., 34, 171.

, Curtis, J., and Kelly, M. (1943). Respiratory metabolism in infancy and in childhood. XXVII. Regulation of body temperature of premature infants. Amer. F. Dis. Child., 65, 376.

Hill, J. R. (1961). The physics and physiology of the development of homeothermy. In Ciba Foundation Symposium on Somatic Stability in the Newly Born, ed. G. E. W. Wolstenholme and M. O'Connor, p. 156. Churchill, London.

Mann, T. P., and Elliott, R. I. K. (1957). Neonatal cold injury due to accidental exposure to cold. Lancet, 1, 229.

Mestyán, J., Fekete, M., Bata, G., and Járai, I. (1964). The basal metabolic rate of premature infants. Biol. Neonat. (Basel), 7, 11.

Přibylová, H., and Znamenáček, K. (1964). Some aspects of thermoregulatory reactions in newborn infants during the first hours of life. ibid., 6, 324.

Scopes, J. W. (1965). Studies in $\mathrm{O}_{2}$ consumption in newborn babies. Ph.D. thesis, London.

and Ahmed, I. (1966a). Minimal rates of oxygen consumption in sick and premature newborn infants. Arch. Dis. Childh., 41, 407.

and - (1966b). Indirect assessment of oxygen requirements in newborn babies by monitoring deep body temperature. ibid., 41, 25.

Silverman, W. A., and Agate, F. J., Jr. (1964). Variation in cold resistance among small newborn infants. Biol. Neonat. (Basel), 6, 113.

, Fertig, J. W., and Berger, A. P. (1958). The influence of the thermal environment on the survival of newly born premature infants. Pediatrics, 22, 876. 